
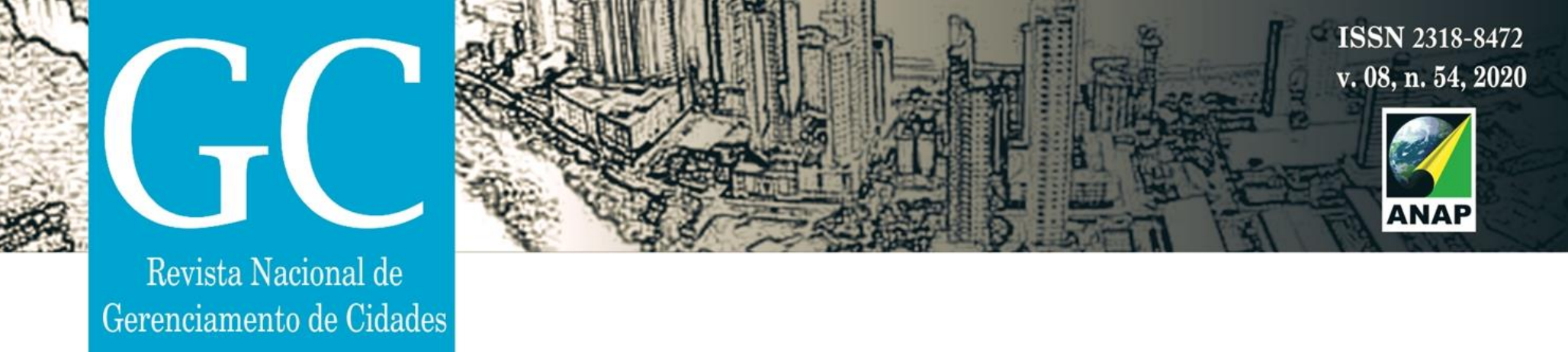

\title{
Avaliação da qualidade ambiental em conjunto habitacional de interesse social: estudo de caso em Oriente-SP
}

\author{
Assessment of environmental quality in housing social interest set: case study in \\ Oriente-SP
}

Evaluación de la calidad ambiental en la vivienda conjunto de interés social: estudio de caso en Oriente-SP

\author{
João Roberto Gomes de Faria \\ Professor Doutor, UNESP, Brasil. \\ joao.rg.faria@unesp.br \\ Maria Solange Gurgel Castro Fontes \\ Professora Doutora, UNESP, Brasil. \\ solange.fontes@unesp.br \\ Natália Fialho de Souza Morini \\ Mestranda, UNESP, Brasil. \\ natalia.morini@hotmail.com
}




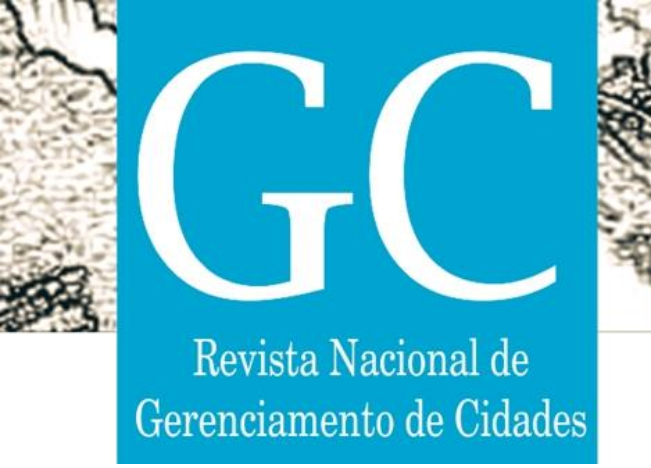

\section{RESUMO}

O índice de qualidade de HIS (Habitações de Interesse social) está relacionado com os investimentos destinados a sanar o déficit habitacional no Brasil, onde se revelou a precariedade e o descuidado dessas habitações que são produzidas com o intuito de abrigar um grande número de famílias. A preocupação com as variáveis ambientais não é tão presente desde a concepção do projeto, deixando de atender a necessidade do morador e seus sentidos quanto a ambiência, ocasionando a falta da qualidade de vida. O presente estudo realizou uma pesquisa qualitativa com os moradores de um conjunto habitacional para avaliar o desenvolvimento dessas habitações, verificando seu impacto e sua qualidade construtiva e ambiental. A metodologia empregada é a Avaliação Pós-Ocupação (APO) e o Painel de Especialistas (PE), onde foram os próprios moradores que analisaram a iluminação, ventilação, acústica, dimensões dos cômodos e conforto térmico em um estudo de caso no conjunto habitacional desenvolvido pela Companhia de Desenvolvimento Habitacional e Urbano (CDHU) no ano de 2003, denominado Ernesto Reis, localizado no interior de São Paulo na cidade de Oriente. Os resultados obtidos revelaram a satisfação dos moradores quanto a casa e o conjunto habitacional. Entretanto foi constatado o melhor nível de satisfação em relação aos cômodos da residência em que já tinham sofrido intervenções em comparação com o que já haviam sido executados.

PALAVRAS-CHAVE: Conforto Ambiental. Interesse social. Habitação horizontal.

\section{ABSTRACT}

The Social Interest Housing $(\mathrm{SIH})$ quality index is related to investments to remedy the housing shortage in Brazil, which revealed the precariousness and carelessness of these dwellings that are produced in order to shelter a large number of families. The concern with environmental variables is not so present since the project conception, failing to meet the need of the resident and his senses as the ambience, causing the lack of quality of life. The present study conducted a qualitative research with the residents of a housing development to evaluate the development of these dwellings, checking their impact and their constructive and environmental quality. The methodology employed is the PostOccupancy Evaluation (POE) and the Expert Panel (PE), in which the residents themselves analyzed the lighting, ventilation, acoustics, room dimensions and thermal comfort in a case study in the housing development developed. by the Housing and Urban Development Company (CDHU) in 2003, named Ernesto Reis, located in the interior of São Paulo State in the city of Oriente. The obtained results revealed the satisfaction of the residents regarding the house and the housing development. However, it was found the best level of satisfaction in relation to the rooms of the residence in which they had already undergone interventions compared to those that had already been executed.

KEYWORDS: Environmental comfort. Social interest. Horizontal housing.

\section{RESUMEN}

El índice de calidad de Habitácion de Interés Social (HIS) está relacionado con inversiones para remediar la escasez de viviendas en Brasil, que reveló la precariedad y el descuido de estas viviendas que se producen para albergar a un gran número de familias. La preocupación por el confort ambiental no está tan presente desde la concepción del proyecto, al no satisfacer la necesidad del residente y sus sentidos como el ambiente, provocando la falta de calidad de vida. El presente estudio realizó una investigación cualitativa con los residentes de un desarrollo de viviendas para evaluar el desarrollo de estas viviendas, verificando su impacto y su calidad constructiva y ambiental. La metodología empleada es la APO (Evaluación de la ocupación posterior) y el Panel de expertos (PE), donde los propios residentes analizaron la iluminación, la ventilación, la acústica, las dimensiones de la habitación y el confort térmico en un estudio de caso en el desarrollo de viviendas desarrollado. por la Empresa de Vivienda y Desarrollo Urbano (CDHU) en 2003, llamada Ernesto Reis, ubicada en el interior del Estado de São Paulo en la ciudad de Oriente. Los resultados obtenidos revelaron la satisfacción de los residentes con respecto a la casa y el desarrollo de la vivienda. Sin embargo, se encontró el mejor nivel de satisfacción en relación con las habitaciones de la residencia en las que ya se habían sometido a intervenciones en comparación con las que ya se habían ejecutado.

PALABRAS CLAVE: Confort ambiental. Interés social. Vivienda horizontal. 


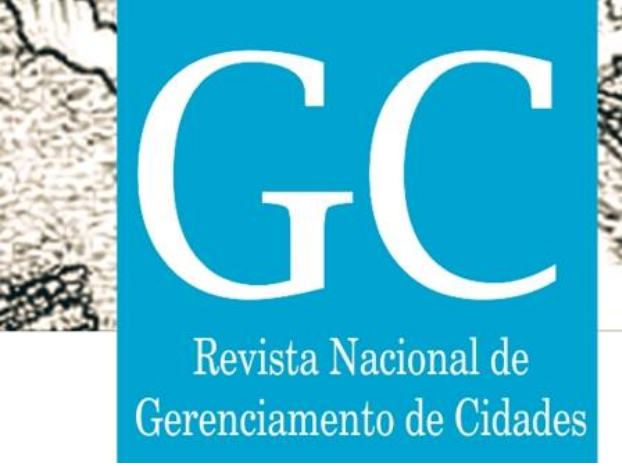

\section{OBJETIVO}

Analisar a qualidade e a percepção ambiental (térmica, acústica e da iluminação) de conjunto habitacional horizontal desenvolvido pela CDHU, com estudo de caso na cidade de Oriente/SP.

\section{METODOLOGIA}

A pesquisa se enquadra como descritiva e é realizada através da análise de um estudo de caso. Foram utilizados métodos e técnicas de Avaliação Pós-ocupação (APO). Considerando sua conceituação básica, aplicação de técnicas de APO deve levar sempre em consideração tanto o ponto de vista técnico (vistorias, medições e análises), como a satisfação dos usuários (ORNSTEIN; ROMÉRO; 2003). Os procedimentos metodológicos são organizados como: apresentação do conjunto habitacional e suas características, coleta de dados, apresentação de resultados e conclusão. As unidades habitacionais, quando entregues no ano de 2003, possuíam 39,56 metros de área segundo seu memorial descritivo. As residências eram compostas de dois quartos, cozinha com sala integrada, e um banheiro.

\subsection{CARACTERIZAÇÃO DO ESTUDO DE CASO}

O conjunto habitacional estudado foi o Ernesto Reis construído pela CDHU e entregue no ano de 2003. Foi o primeiro conjunto da cidade de Oriente (SP). Segundo o IBGE, a população estimada para a cidade é de 6.487 habitantes. 

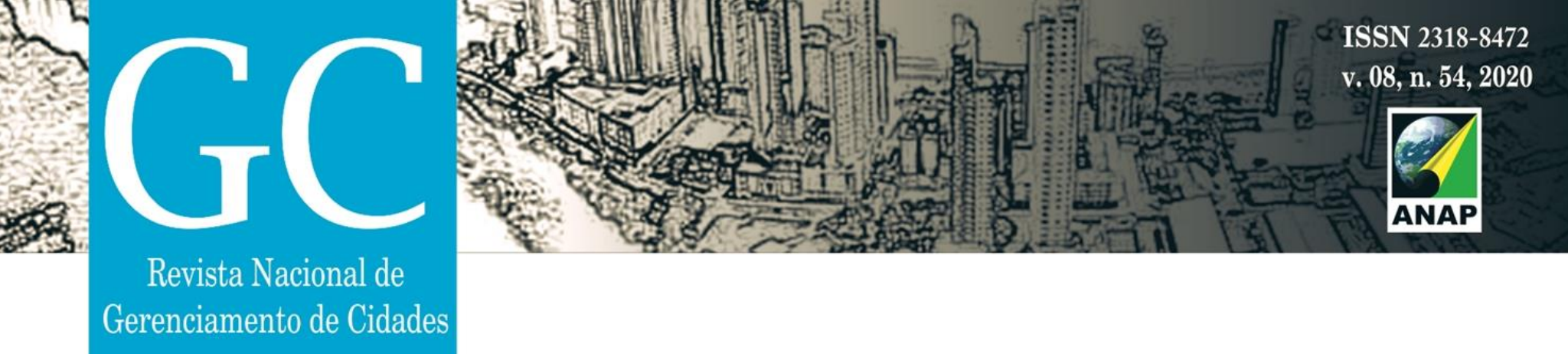

\subsection{ANÁLISE DE DADOS}

As questões fechadas foram analisadas através de gráficos de frequência, enquanto as questões abertas foram avaliados descritivamente os temas mais citados pelos moradores.

\section{4- RESULTADOS}

\subsection{VISTORIA TÉCNICA}

As casas foram projetadas com dois quartos, um banheiro, cozinha e sala integrados e uma lavanderia descoberta do lado externo; entretanto não possuíam piso, forro e azulejo nos banheiros e na cozinha, o que resultou nas diversas alterações encontradas hoje, e que foram necessárias para o maior conforto de seus moradores.

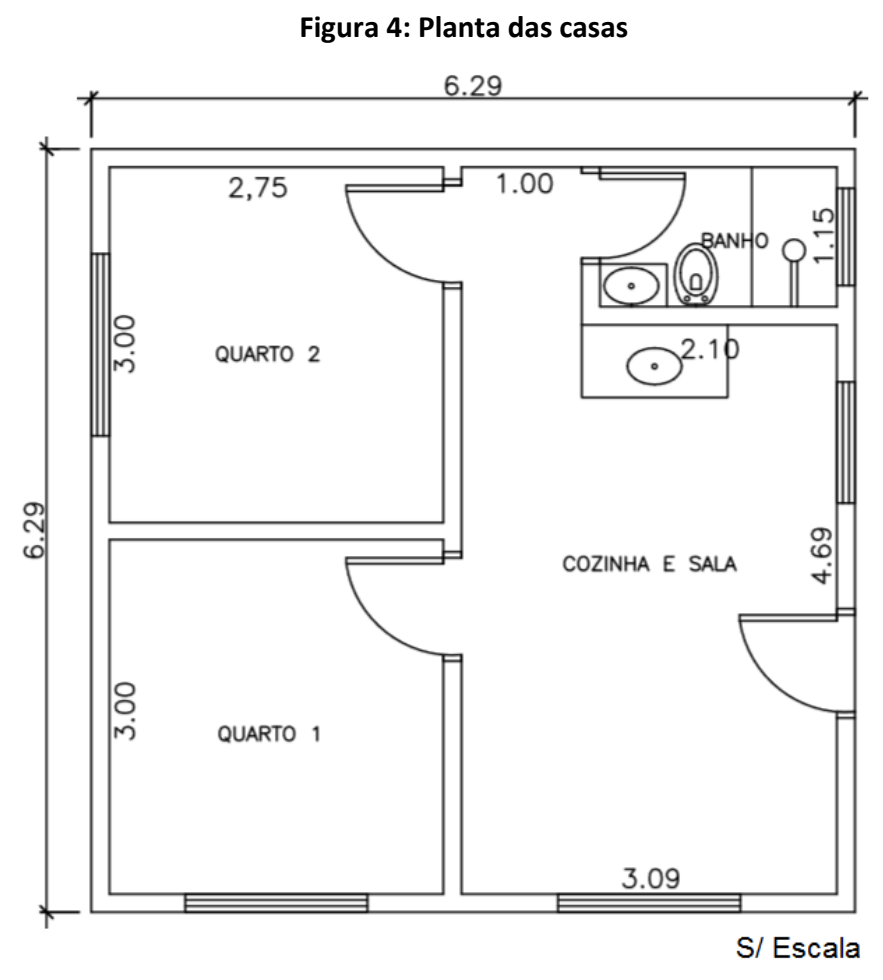

Fonte: Autores, 2019 

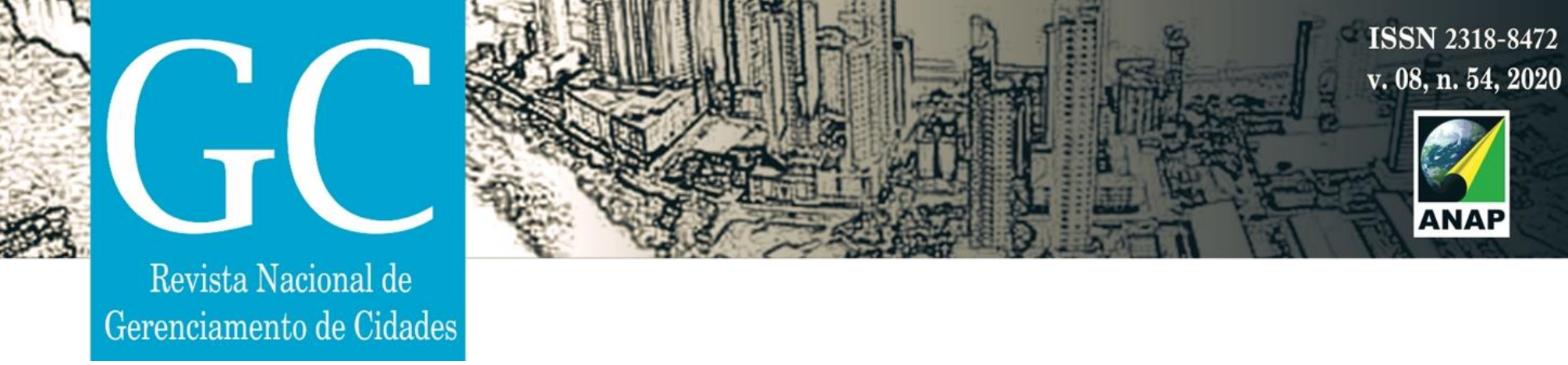

\subsection{RESIDÊNCIAS COM ALTERAÇÕES}

Para mostrar a diferença entre as casas ampliadas e as com reformas figura 5 (A) mostra uma das poucas casas sem alterações, e a figura 5 (B) revela como esta hoje a maioria das residências.

(A)

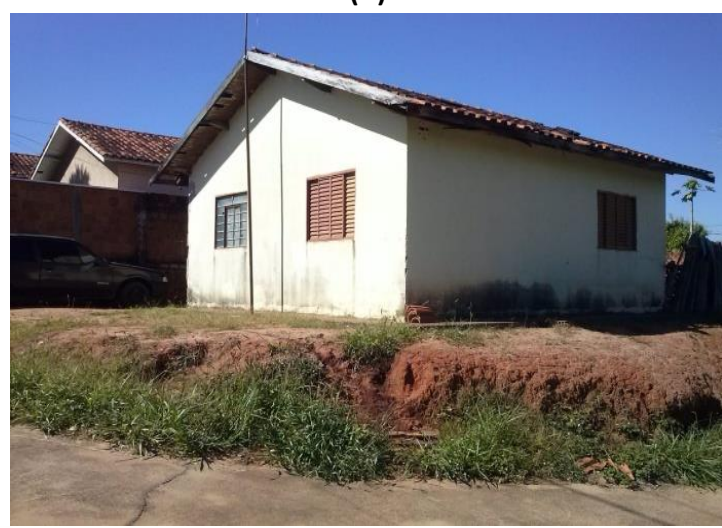

Fonte: Autores, 2019
Figura 5: Casa sem e com alterações

(B)

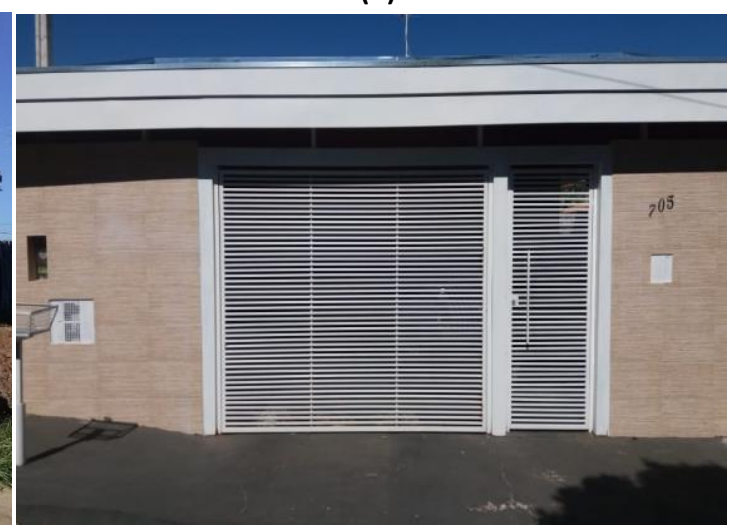

Essas ampliações ocorreram em 22 casas (52,38\%) e o motivo alegado pelos moradores foi a melhoria da qualidade de vida no local. Elas ocorreram na área externa, na sala e na cozinha, onde esta por serem integradas acabaram sendo muito pequenas. É nítida a diferença daqueles que conseguiram ampliar o projeto de suas casas, conforme a comparação das figuras 6 (A) e 6 (B) do interior da residência, melhorando a satisfação geral com o lar.

Figura 6: Interior da residência com aumento de cozinha

(A)

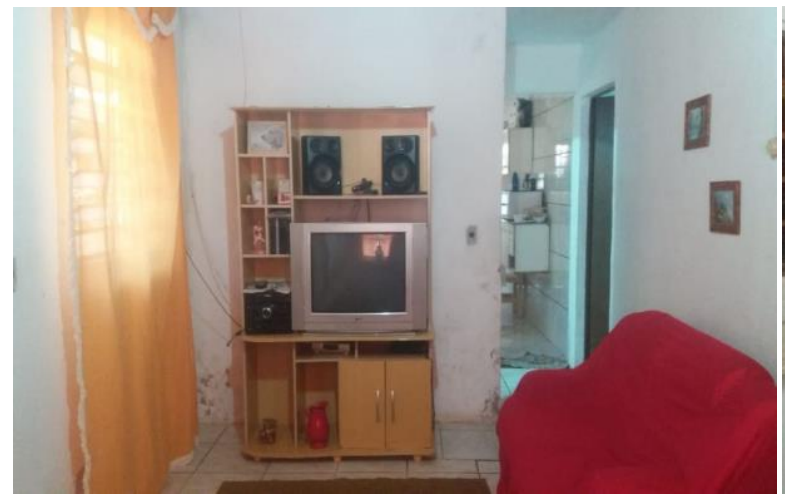

(B)

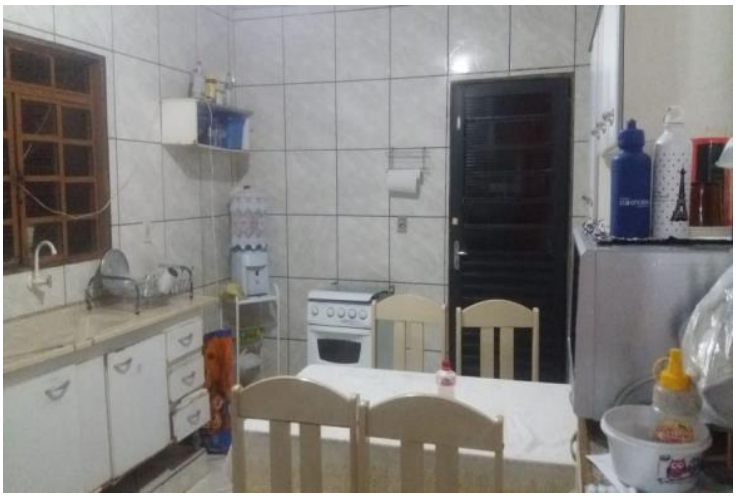

Fonte: Autores, 2019 


\section{$\mathrm{GC}$}

\subsection{CARACTERISTICAS DOS MORADORES}

A maior parte dos entrevistados é adulta, com predominância da faixa de 46 a 60 anos (Figura 7) e reside na casa desde 2003 (Figura 8).

Figura 7. Distribuição dos moradores entrevistados por faixa etária

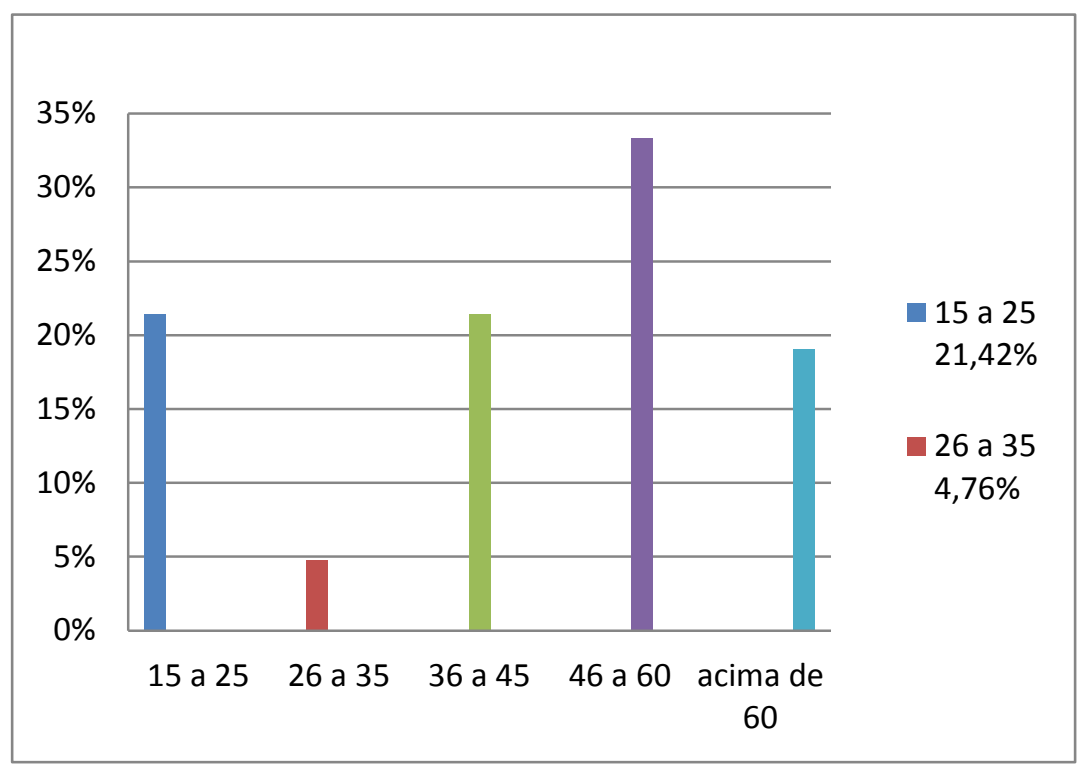

Fonte: Autores, 2019

Figura 8. Distribuição dos moradores entrevistados por tempo de moradia no local

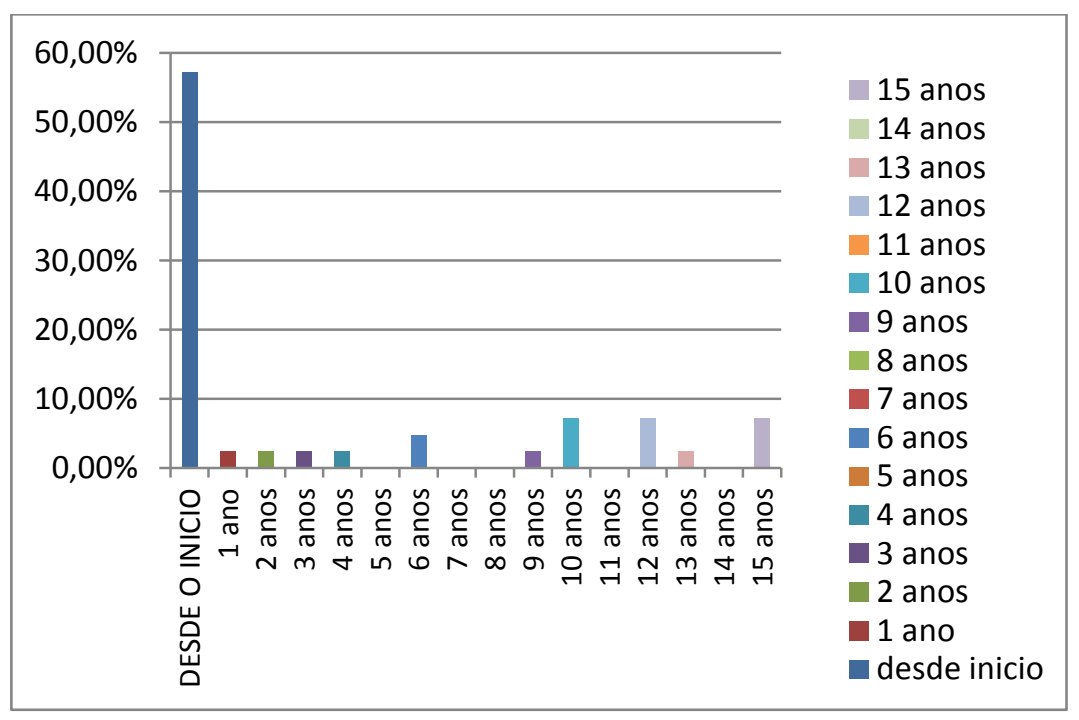

Fonte: Autores, 2019 


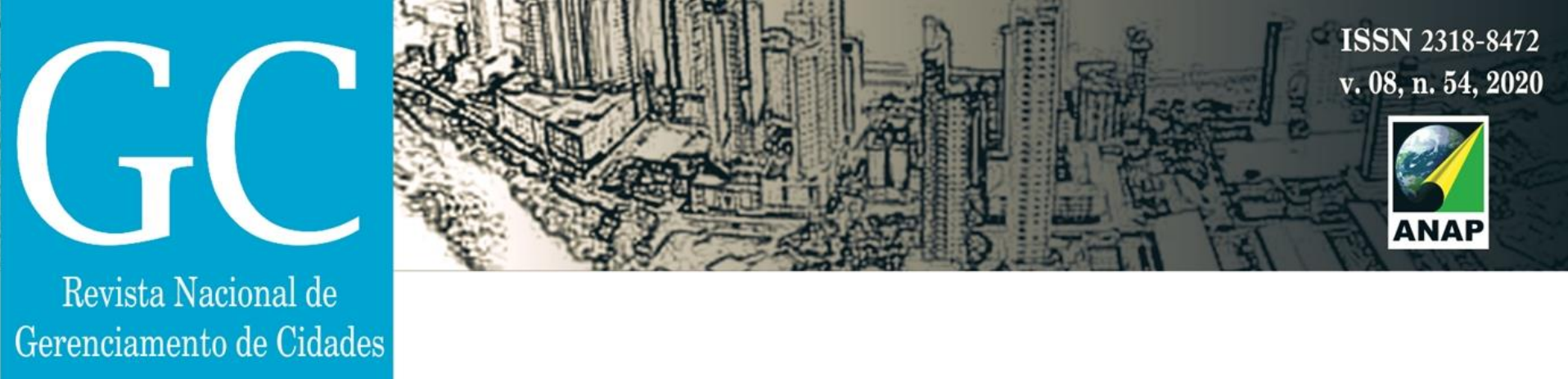

\subsection{DESEJO DOS MORADORES (QUESTÕES ABERTAS)}

Ao adotar o critério do PE (Painel de Especialistas), onde os próprios moradores analisam sua habitação, foi analisado as respostas com maior frequiência de assuntos citados pelos moradores referentes ao que mais gostam na casa ou no conjunto habitacional. As respostas mais frequentes foram: conjunto habitacional agradável (25\%), boa vizinhança com (32\%) e a tranqüilidade do local com (44\%), destacando a proximidade do posto de saúde (76\%). Porém, 10 questionários tiveram como respostas "nada" com (24\%).

Para o que menos gostam predominou a sujeira nas ruas, distância do comércio e a casa que foi entregue em 2013, há 16 anos, sem forro e sem piso, onde alguns moradores não conseguiram colocar por conta de suas condições financeiras. Sobre o que mudariam, os moradores ressaltaram a questão do forro e do piso, além de ampliar os cômodos da residência. No conjunto habitacional, especificamente nas ruas, a resolução seria colocar mais quebra-molas nas ruas, e para os moradores que residem na rua Joaquim Abreu Luz, constatou a necessidade de uma calçada na divisa com o cemitério municipal, o que acaba ocasionando muita sujeira na rua.

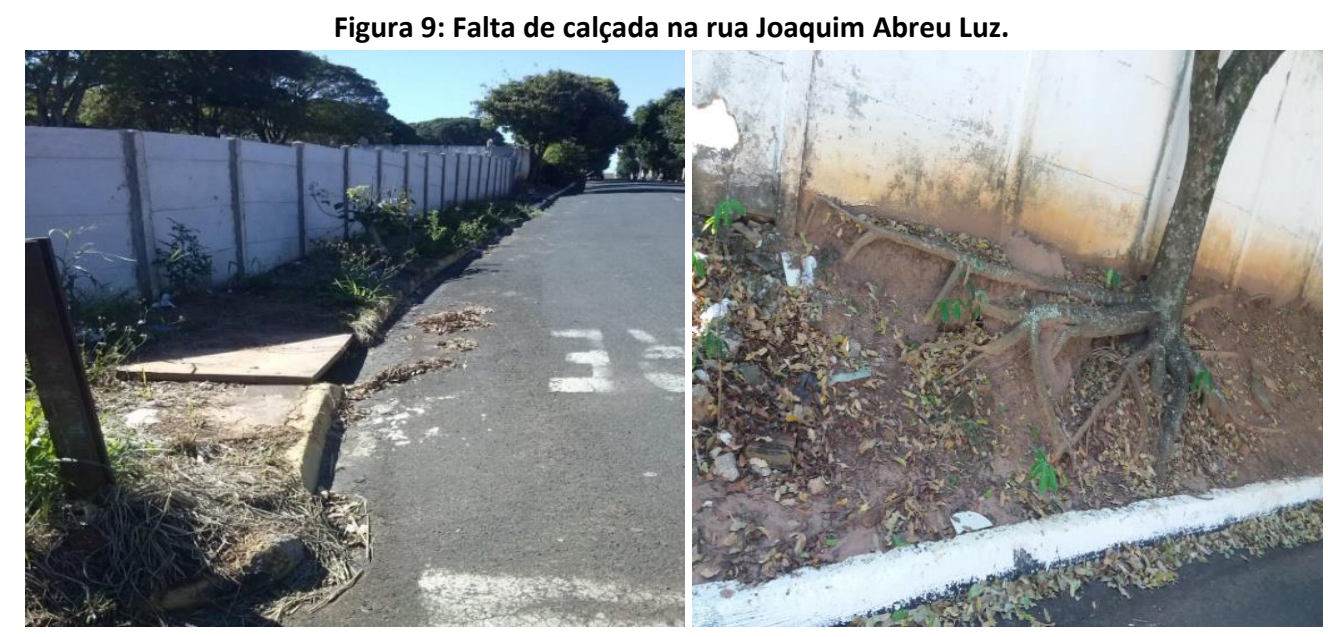

Fonte: Autores, 2019

\subsection{ILUMINAÇÃO NATURAL}

Os moradores entrevistados se mostraram satisfeitos com a iluminação natural dos cômodos da residência à maioria das questões (figura 10), nas quais a resposta predominante foi 'bom'. 0 quarto obteve o maior índice (67\%) devido à posição da janela, onde o sol é predominante na maior parte do dia. 
Revista Nacional de Gerenciamento de Cidades

Figura 10: Distribuição dos resultados das questões sobre a iluminação natural
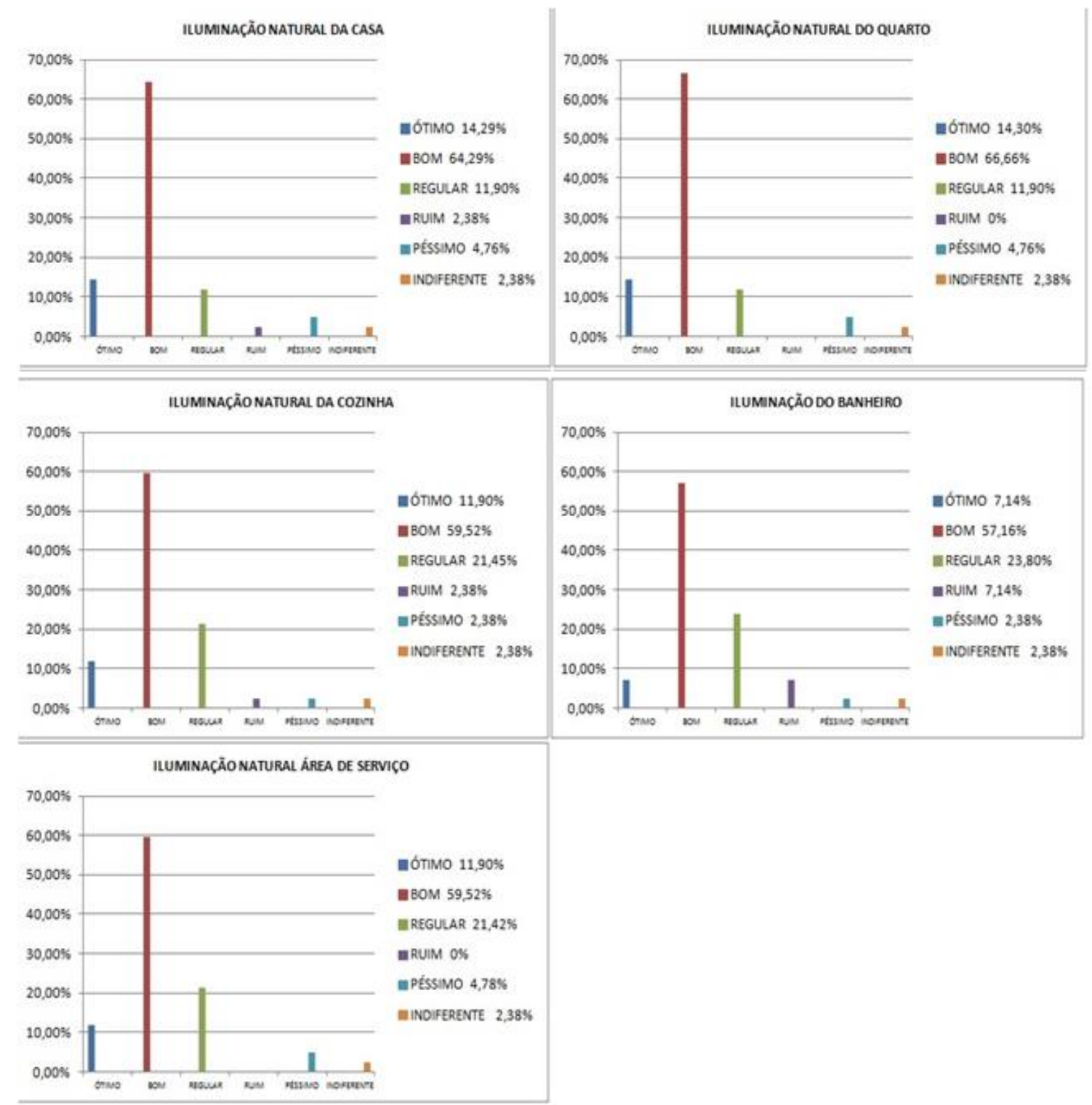

Fonte: Autores, 2019 


\section{$\mathrm{GC}$ \\ Revista Nacional de Gerenciamento de Cidades}

\subsection{CONFORTO TÉRMICO}

Figura 11: Distribuição dos resultados das questões sobre sensação e percepção térmica

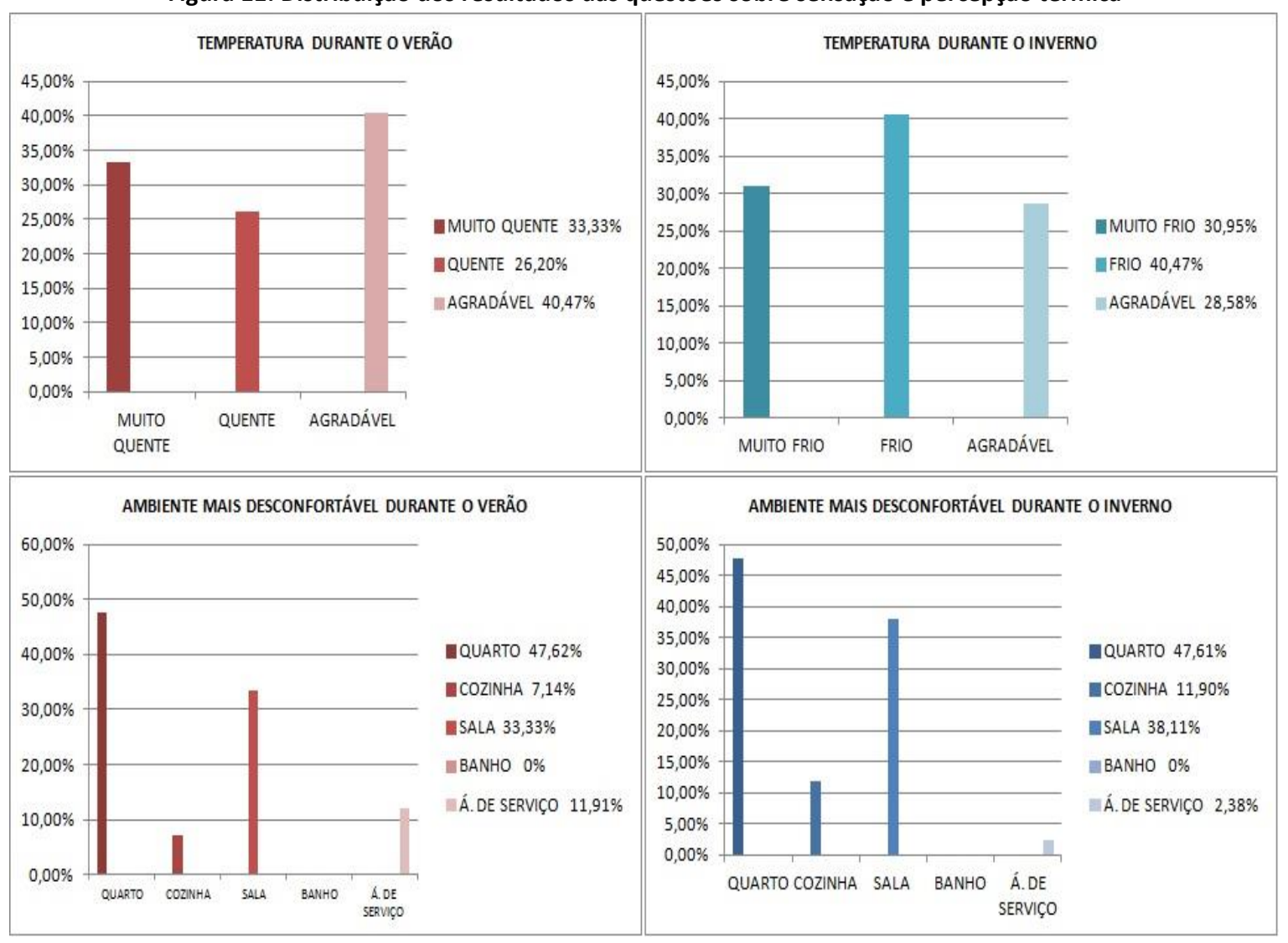

Fonte: Autores, 2019

Os resultados referentes à percepção térmica dos habitantes no verão revelou-se ser agradável (40,5\%), diferentemente do inverno, no qual se constatou ser frio (também 40,5\%), principalmente no quarto onde o mesmo é agradável no verão, o que pode ser justificado pela ausência da incidência solar na parede e, também, em algumas casas, a falta de forro.

\subsection{VENTILAÇÃO NATURAL}

A análise (Figura 12) constatou uma elevada satisfação dos moradores em relação á ventilação da casa, sendo a maior da área de serviço, por já se localizar em um ambiente externo. No ambiente interno, a predominância foi a da sala, o que se deve ao fato de haver mais aberturas.

$\mathrm{O}$ quarto foi o ambiente em que as pessoas mais sentiram a falta de ventilação, sendo o primeiro voltado para a fachada o mais predominante, por conta dos muros altos e portões muito fechados. 


\section{$\mathrm{GC}$ \\ Revista Nacional de \\ Gerenciamento de Cidades}

Figura 12: Distribuição dos resultados das questões sobre ventilação

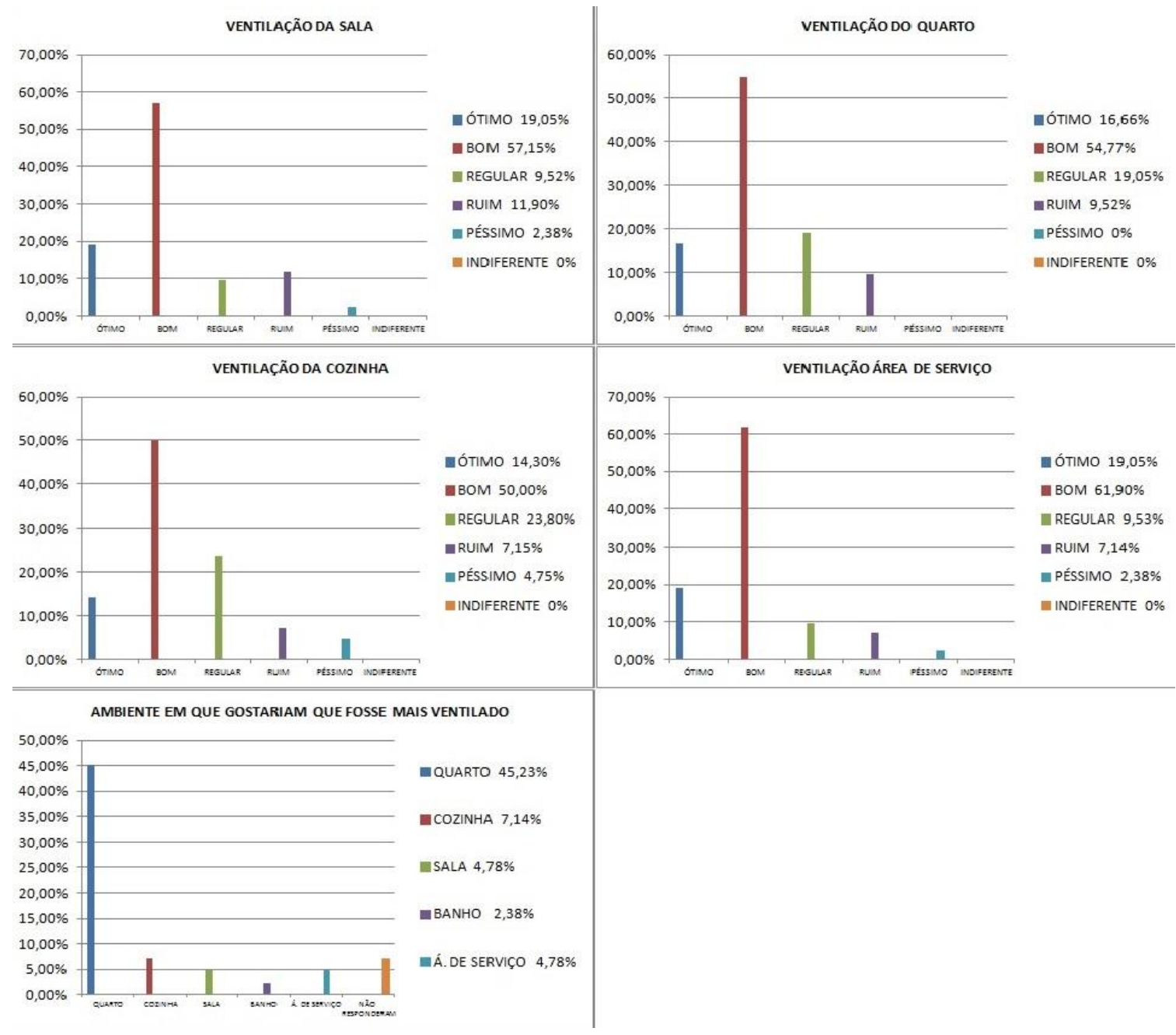

Fonte: Autores, 2019

\subsection{ACÚSTICA}

Em relação ao barulho da rua (Figura 13), a melhor classificação foi a regular, porque depende particularmente de onde se localiza a residência, sendo a sala o cômodo no qual o incômodo é maior. Em contrapartida, o cômodo no qual o ruído interno mais incomoda é o quarto, por sua proximidade com o lado externo da residência e por ser o local onde as pessoas mais esperam por tranqüilidade e por vezes não conseguem. Dentre os ruídos, o que mais incomoda é o da rua, pela passagem de automóveis e outros diversos. 

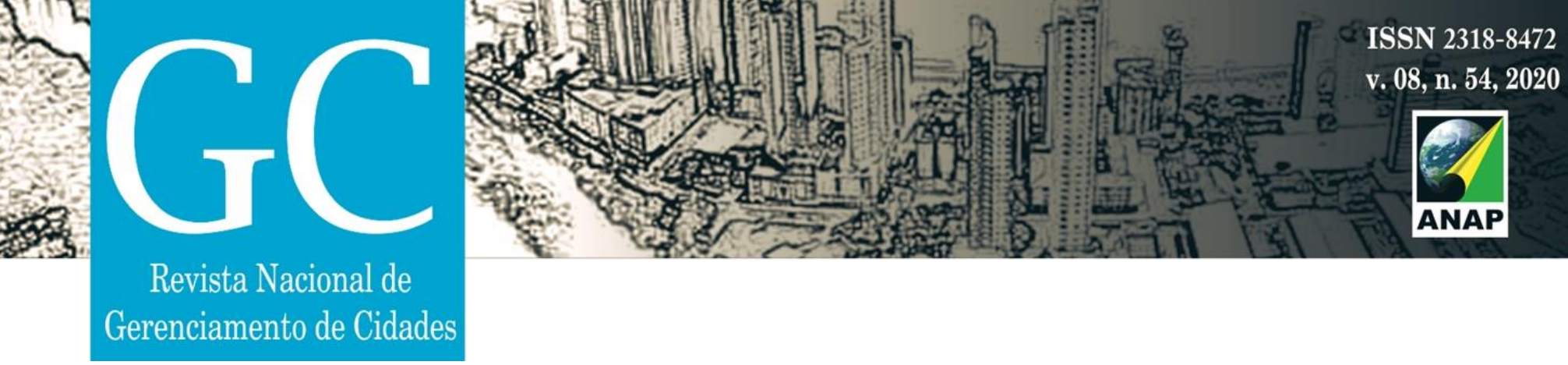

Figura 13: Distribuição dos resultados das questões sobre acústica

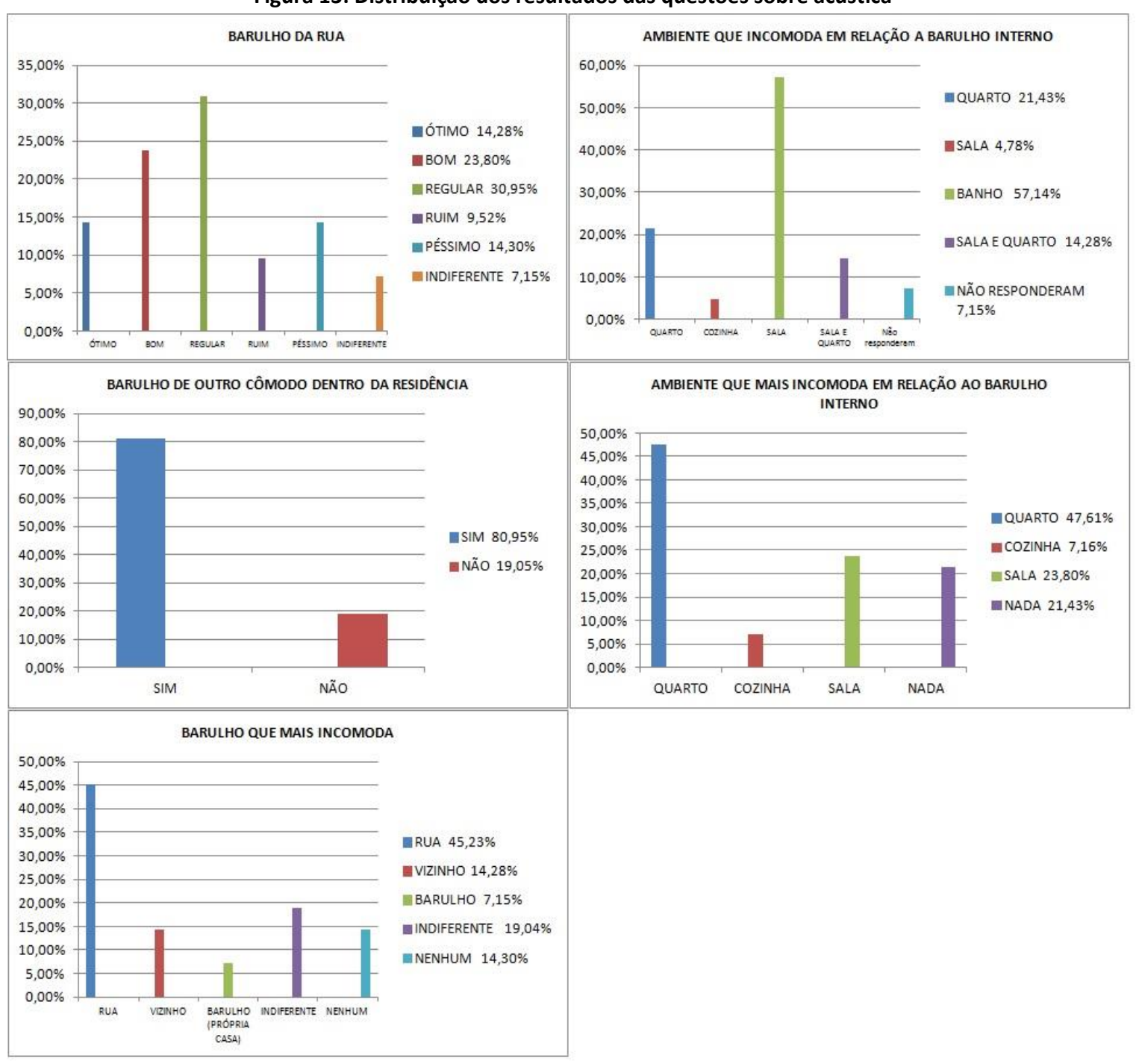

Fonte: Autores, 2019

\subsection{DIMENSÕES DAS CASAS E CÔMODOS}

Com os resultados dos questionários (figura 14), notou-se a satisfação dos moradores quanto ao tamanho da residência, sendo a maior porcentagem em relação aos quartos e a menor em relação a cozinha e ao banheiro. No entanto, percebeu-se durante a aplicação dos questionários que grande parte das habitações foram ampliadas. 


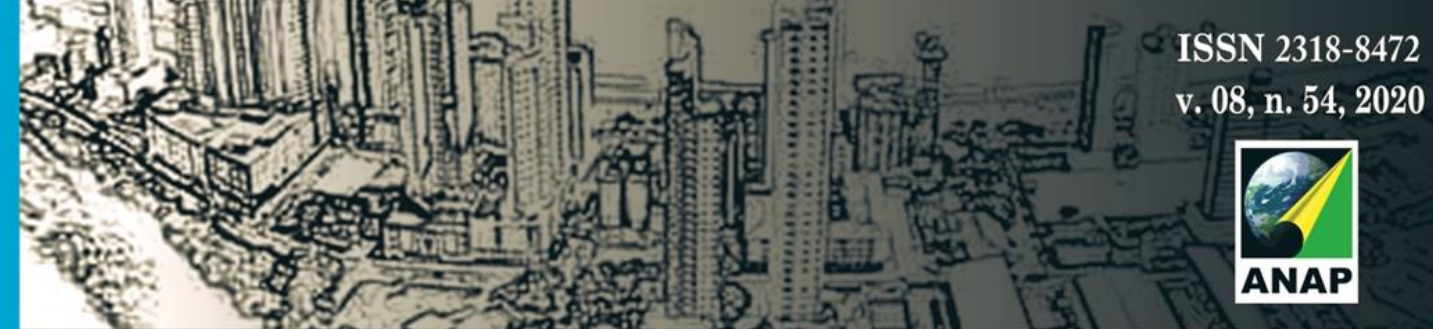

Revista Nacional de Gerenciamento de Cidades

Figura 14: Distribuição dos resultados das questões sobre dimensão

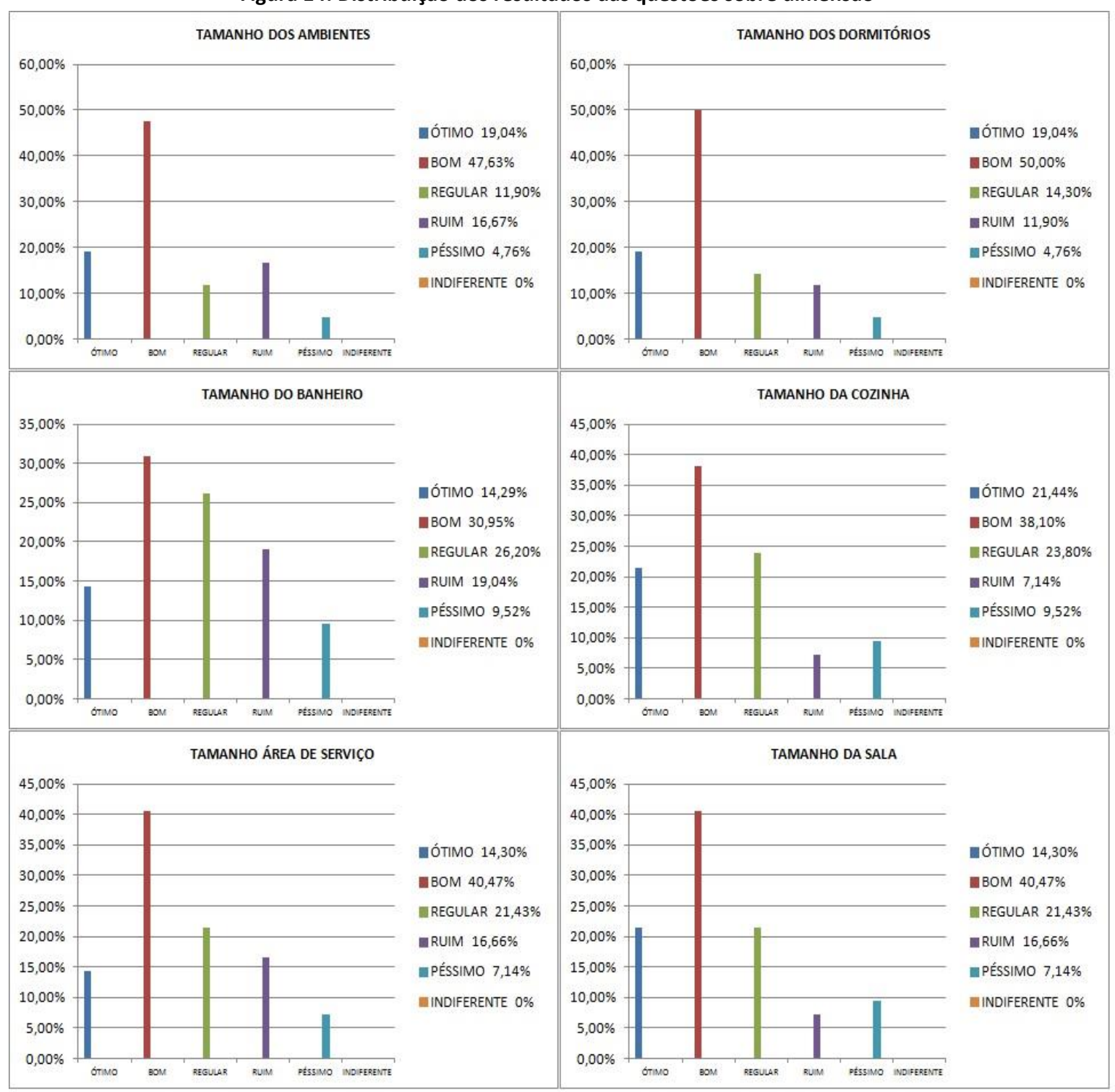

Fonte: Autores, 2019

\section{CONCLUSÕES}

O conjunto habitacional de interesse social Ernesto Reis, localizado em Oriente, interior de São Paulo e desenvolvido pela CDHU no ano de 2003, possui sua tipologia clássica estrutural de projetos desenvolvidos pela empresa do Governo Estadual. A fim de analisar a percepção ambiental e a qualidade das moradias, o presente estudo avaliou a opinião dos moradores do local. Verifica-se que pouco mais da metade dos moradores reside no localdesde sua implantação e que a a maioria das casas sofreram adaptações e ampliações para atender à necessidades das 


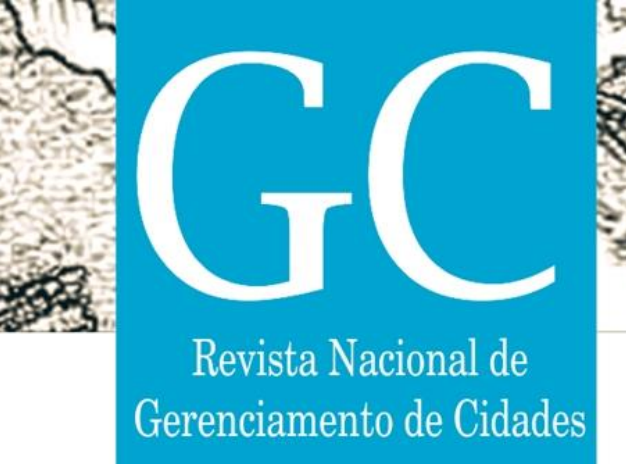

famílias. A qualidade ambiental é, de forma geral, boa, com exceção da situação térmica no inverno. $\mathrm{O}$ quarto foi apontado como o cômodo mais desconfortável quente no verão e frio no inverno, inclusive com ventilação deficiente.

Ao analisar as repostas sobre as questões sociais, se fizeram evidente como as alterações predominantes em grande parte das moradias do conjunto habitacional, que ao longo do tempo foi se diferenciando das habitações daqueles mais carentes. $O$ que se constatou foi o melhor conforto térmico em relação aos cômodos da residência em que já havia executado as reformas daqueles que ainda planejam executar as extensões e reparações, gerando maior descontentamento apesar de serem minorias. Por fim, conclui-se que para se obter moradia de qualidade e conforto térmico satisfatórios para todos, é importante que desde a concepção do projeto, a sua execução e entrega atenda a necessidade dos moradores de imediato evitando custos adicionais ao longo dos anos na habitação.

\section{6- REFERÊNCIAS BIBLIOGRÁFICAS}

BARON, Cristina Maria Perissinoto. A Produção da habitação e os conjuntos habitacionais dos institutos de aposentadorias e pensões - IAPs. 2011. Disponível em:

<http://revista.fct.unesp.br/index.php/topos/article/viewFile/2287/2092>. Acesso em: 19 fev. 2016.

BONDUKI, Nabil. Origens da Habitação Social no Brasil. 4. ed. São Paulo: Estação Liberdade, 2004.

BRASIL. Instituto Brasileiro de Geografia e Estatística. Cidades@. Disponível em: https://cidades.ibge.gov.br/ brasil/ sp/oriente/panorama. Acesso em: 15 jul. 2019.

FERREIRA, Antônio Domingos Dias. Habitação de Interesse Social: Aspectos Históricos, Legais e Construtivos. Rio de Janeiro: Interciência, 2015. 140 p.

FOLZ, Rosana Rita. Mobiliário na habitação popular: Discussões de alternativas para melhoria da habitabilidade. 2. ed. São Carlos: Rima, 2003. 179 p.

FROTA, Anésia Barros; SCHIFFER, Sueli Ramos. Manual de Conforto Térmico. 5. ed. São Paulo: Studio Nobel, 2001. $243 \mathrm{p}$.

MOREIRA, Vera Lúcia Barradas; PINA, Silvia Mikami Gonçalves. Mais do mesmo? A trajetória da habitação social no Brasil. Paranoá: cadernos de arquitetura e urbanismo, [s.l.], n. 6, p.83-91, 31 dez. 1969. Programa de Pos-Graduacao em Arquitetura e Urbanismo - Univ. de Brasilia. http://dx.doi.org/10.18830/issn.1679-0944.n6.2012.12278.

ROMÉRO, Marcelo de Andrade; ORNSTEIN, Sheila Walbe. AVALIAÇÃo PÓs OCUPAÇão: Métodos e Técnicas Aplicadas a Habitação Social. Porto Alegre: Habitare, 2003. 294 p.

SILVA, Marcos Felipe Alves da; SILVA, Renata Braga Aguilar da; FONTES, Maria Solange Gurgel de Castro. Avaliação da qualidade habitacional da arquitetura modernista: estudo de caso em Bauru-SP. Gc: Revista Nacional de Gerenciamento de Cidades, Bauru, v. 6, n. 43, p.11-24, jan. 2018. 